\title{
Identidad boyacense: cultura popular, floklor y carranga (1960-1980)*
}

\section{Resumen}

Durante los años sesenta, en Colombia se avizoraron cambios importantes en el ámbito cultural (desarrollo del Instituto Colombiano de Cultura) y en la vida política (incursión de movimientos que promovieron mayor participación de los sectores populares). Particularmente en Boyacá se presentó un gran interés por definir la identidad del boyacense y por promover el desarrollo cultural. En este texto se analiza cómo se pretendió caracterizar la identidad del boyacense (1960-1980), para lo cual se realizó un análisis hermenéutico de la información documental colectada para establecer las dimensiones aquí descritas: folclor y cultura popular; identidad regional; música carranguera. Se evidenció una dicotomía entre las perspectivas folclorista y cultura popular de los estudiosos de la época. Desde la folclorogía se promovió la formación musical centro europea y como expresión popular se consolida la música carranguera, con la cual se populariza la vida cotidiana de los campesinos.

\section{Palabras clave}

Tesauro: cultura popular, folklore, identidad nacional.

Autor: música de carranga.

Referencia bibliográfica para citar este artículo: Acuña Rodríguez, Olga Yanet y otros. "Identidad boyacense: cultura popular, floklor y carranga (1960-1980)". Anuario de Historia Regional y de las Fronteras 24.1 (2019): 35-56.

Olga Yanet Acuña Rodríguez: doctora en Historia de América Latina de la Universidad Pablo de Olavide, España. Magíster en Historia y licenciada en Ciencias Sociales. Profesora de la Universidad Pedagógica y Tecnológica de Colombia. Editora de la Revista Historia y Memoria. Código ORCID: https://orcid. org/0000-0001-6273-2715. Correo electrónico: olga.acuna@uptc.edu.co.

Ruth Nayibe Cárdenas Soler: doctora en Educación Musical de la Universidad de Granada, España. Magíster en Educación, máster en Educación Musical, especialista en Dirección de Orquesta y licenciada en Música. Profesora de la Universidad Pedagógica y Tecnológica de Colombia. Código ORCID: https:// orcid.org/0000-0003-4997-4116. Correo electrónico: ruth.cardenas@uptc.edu.co.

Julio Aldemar Gómez Castañeda: doctor en Historia de la Universidad Pedagógica y Tecnológica de Colombia. Especialista en Gerencia Educativa y licenciado en Música. Profesor de la Universidad Pedagógica y Tecnológica de Colombia. Código ORCID: https://orcid.org/0000-0003-0045-4574. Correo electrónico:juliomus@gmail.com.

\footnotetext{
* Artículo producto de la investigación "La cultura en Tunja: un panorama entre lo culto, lo popular y lo tradicional (1970-1980)-SGI 2191”, financiada por la Universidad Pedagógica y Tecnológica de Colombia.
} 


\title{
Boyacense Identity: Popular Culture, Folklore and Carranga (1960-1980)
}

\begin{abstract}
During the 1960's, important changes were observed in the cultural sphere of Colombia (development of the Instituto Colombiano de Cultura) and in political life (incursion of movements which enable popular sectors to have greater participation). Particularly in Boyacá, there was a great interest to define the Boyacense identity and to promote cultural development. In this paper, it is analysed how it was intended to characterize the Boyacense identity (1960-1980), for which a hermeneutic analysis of the collected documentary information was carried out in order to establish the dimensions described here: folklore and popular culture; regional identity; Carranguera music. It was evidenced a dichotomy between the folklorist perspectives and popular culture of the scholars of that period. From folklore studies, it was promoted central European music training traditional music and as a popular expression the Carranguera music is consolidated which popularised rural life.
\end{abstract}

Keywords

Thesaurus: Popular Culture, Folklore, National Identity.

Author's keywords: Carranga Music.

\section{Identidade boyacense: cultura popular, folclore e carranga (1960-1980)}

\section{Resumo}

Durante os anos 60, mudanças importantes foram observadas na Colômbia na esfera cultural (desenvolvimento do Instituto Colombiano de Cultura) e na vida política (incursão de movimentos que promoveram maior participação dos setores populares). Particularmente em Boyacá houve um grande interesse em definir a identidade dos naturais de Boyacá e promover o desenvolvimento cultural. Este texto analisa como pretendeu caracterizar a identidade do Boyacense (1960-1980), para a qual foi realizada uma análise hermenêutica das informações documentais coletadas para estabelecer as dimensões descritas aqui: folclore e cultura popular; identidade regional; Música Carranguera. Se evidenciou uma dicotomia entre as perspectivas folclorista e cultura popular dos estudiosos da época. Dos estudos folclóricos foi promovida a formação musical do centro da Europa e como expressão popular, se consolida a música carranguera, com a que se difunde o cotidiano dos camponeses.

\section{Palavras-chave}

Tesauro: cultura popular, folklor, identidade nacional.

Palavras-chave do autor: música carranga. 


\section{Introducción}

Desde los años sesenta y setenta del siglo XX se percibió un interés, de un grupo de estudiosos de la cultura, por indagar sobre la identidad del boyacense, con miras a reconocer sus tradiciones, valores y manifestaciones culturales; de tal manera que estos dieran cuenta de una noción de región, para tratar de analizar sus interacciones en torno a la consolidación de la nación, un interés que surge desde comienzo del siglo XX, cuando se relaciona folclor con indigenismo. ${ }^{1}$ Así, desde una perspectiva funcionalista, se pretendió ver la definición de la identidad de las regiones-partes, y su articulación con la nación -dentro de un todo. En ese orden de ideas, se ubicó la atención en las expresiones musicales para tratar de encontrar aspectos centrales de la cultura del boyacense, a partir de estudios que se acercaron más a la folclorología, ubicándose en la cultura de élite. Otra tendencia se concentró más en los saberes y tradiciones populares, retomando experiencias y manifestaciones propias de los campesinos, lo que los ubicó cerca de la cultura popular.

El interés por el estudio de las manifestaciones culturales ha permitido el rastreo, desde la historia cultural, de algunas reflexiones que permitieron caracterizar las expresiones culturales del boyacense y ver de qué manera se construye una identidad. Al respecto, son sustanciales los aportes de Peter Burke, ${ }^{2}$ quien expone el concepto de cultura popular como cultura del pueblo, refiriéndose a las diversas manifestaciones de los habitantes del área rural, cuyas labores y dinámicas no son idénticas ni homogéneas. Según este autor, hay muchas culturas populares o muchas variedades de cultura popular. Sobre el concepto de cultura popular, Carlo Guinzburg ${ }^{3}$ sostiene que su uso se asocia a la antropología cultural, por tanto, el estudio de las actitudes, creencias y patrones de comportamiento, que antes eran analizados por la folclorología y ahora son objeto de investigación de varias disciplinas. Sin embargo, en este caso particular, nos centramos en la cultura popular producida por las clases populares y no en la cultura impuesta a estos grupos sociales ${ }^{4}$; sin desconocer que en los años setenta se produjo esa dicotomía que fue importante para estudiar y reivindicar la identidad del boyacense.

El texto está estructurado en tres partes: en la primera se plantea el debate entre las tendencias que se ocupan en la década de los años setenta del estudio de la cultura, es decir, la tendencia de la folclorología y la tendencia de la cultura popular, la primera centrada en la música y la danza, y la segunda en las representaciones y expresiones propias de los sectores populares. En el segundo aparte se describe cómo un grupo de estudiosos pretendió encontrar en los rasgos indígenas muiscas y su mezcla con lo hispano el semblante de identidad del boyacense, prevaleciendo la

\footnotetext{
${ }^{1}$ Óscar Javier Barrera Aguilera, "Folclor, indigenismo y mestizaje durante la república liberal”, Maguaré 23 (2009): 136.

2 Peter Burke, La cultura popular en la Europa Moderna (Madrid: Alianza, 1991) 68-69.

${ }^{3}$ Carlo Guinzburg, El queso y los gusanos, el cosmos según un molinero del siglo XVI(Barcelona: Ediciones Península, 1981) 12.

${ }^{4}$ Renán Silva, República Liberal, intelectuales y Cultura Popular (Medellín: La Carreta Editores, 2012).
} 
cultura hispana, lo cual potenciaría la cultura de las élites desde la folclorología. En el tercer aparte se analiza cómo surgió la música carrangera, que, bajo un proceso de indagación sobre la cultura campesina, consiguió articular: saberes, dichos, lenguajes y melodías, convirtiéndose esta música en expresión de la cultura popular de los campesinos del territorio denominado "altiplano cundiboyacense".

\section{Entre folclor y cultura popular}

En los años setenta, en Boyacá, el estudio sobre la cultura fue de gran relevancia, ya que desde allí se pretendió encontrar algunos referentes sobre identidad de los pueblos y la forma en que se integraron a la consolidación de la identidad nacional. En ese contexto, se percibió un interés sustancial por los estudios culturales, tanto de las élites, a través de la música y del arte, como de los sectores populares, para dar cuenta de sus representaciones, expresiones, tradiciones y lo que en su momento se denominó el folclor, que ocupó un lugar central en las investigaciones respecto a la cultura.

Sobre el concepto de identidad del boyacense en la década de los años setenta, el historiador Javier Ocampo señaló que Boyacá era un departamento cuyos paisajes naturales y conformación étnico-cultural tenía supervivencia indígena e hispánica, elementos que eran referentes fundamentales para la formación de la identidad regional. ${ }^{5}$ La preocupación fundamental fue cómo encontrar y caracterizar la identidad del boyacense. Al respecto, Ocampo López sugiere indagar por la identidad territorial, considerando que el espacio es un componente fundamental de la formación cultural; igualmente el étnico, en el que se deben considerar los diversos aspectos raciales y socio-culturales que se derivan de lo muisca y lo hispano. Sin embargo, señalaba Ocampo, para encontrar rasgos de la identidad colectiva se deberían tener en cuenta: aspectos geográficos, históricos, étnicos, de la mentalidad colectiva y de la historia. ${ }^{6}$

En las reflexiones se perciben dos tendencias de análisis de la cultura: una que reconoce el legado cultural que los españoles les dejaron a los indígenas, que se consideró sustancial para construir, a partir de allí, la identidad cultural del boyacense. Evidencia de ello son los trajes típicos de la región que comprende el actual altiplano cundiboyacense, que tienen un origen español y una adaptación al estilo indígena; además de diferentes bailes coreográficos, como la "danza de las espadas", que simulaba las luchas entre musulmanes y cristianos, y la "gallarda", un baile de salón de origen europeo ${ }^{7}$. Es así como se percibe ciertas representaciones de lo indígena, que podrían sugerir el estudio de la mezcla de hábitos, creencias y formas de pensamiento, que García Canclini denomina "hibridación cultural", 8 para referirse a la mezcla

\footnotetext{
${ }^{5}$ Javier Ocampo López, "Los fundamentos históricos en la formación de los pueblos de Boyacá", Historia y Culturas Populares. Los estudios regionales en Boyacá, comp. Pablo Mora Calderón y Amado Guerrero Rincón (Tunja: Instituto de Cultura y Bellas Artes de Boyacá, Ministerio de Educación Nacional, Instituto Andino de Artes Populares, 1989) 127.

${ }^{6}$ Ocampo López, Los fundamentos históricos 4.

${ }^{7}$ Javier Ocampo López, Música y Folclor de Colombia (Bogotá: Plaza y Janés Editores, 2004) 39.

${ }^{8}$ Néstor García Canclini, Culturas hibridas. Estrategias para entrar y salir de la modernidad (Barcelona:
} 
de colonizadores con indígenas, lo que sugiere que se analicen dichas expresiones como articulación; sin embargo, desde la perspectiva de Ocampo prevalecían más los valores y las representaciones hispanas. Bajo esta mirada, las expresiones culturales: música, arte y literatura, se convirtieron en elementos representativos en el contexto nacional, asociadas a la cultura de élite, que en ocasiones puede ser una forma de imponer y afianzar rasgos de civilización en oposición a la tradición y a lo popular.

Peter Burke 9 resalta que el término folclor, la otra tendencia de análisis, es una palabra de origen inglés usada a mediados de siglo XIX (1846) para referirse a lo popular, específicamente a los cantos y expresiones de la cultura del pueblo. Sobre el concepto de folclor, Ernesto Moreno señaló que a mediados del siglo XIX se produjo un estudio sistemático en el que se pudo apreciar el concepto de pueblo (o gente) y el saber. De esta forma, se pretendió resumir todo lo relativo a un pueblo y su relación con la nación, así se refirió a todo un concepto que representaba: tradiciones populares, baladas legendarias, narraciones, tradiciones, cuento de héroes, antiguas costumbres, leyendas, cuentos populares, proverbios locales y dichos vulgares; asimismo, juegos, canciones y en general diversas expresiones del pueblo. En Inglaterra un grupo de estudiosos de las leyendas y tradiciones populares siguieron cultivando esta rama del saber y lo convirtieron en objeto de estudio, esta fue la base para consolidar la Sociedad Folclórica en Londres, encargada de estudiar el concepto de folclor y sus manifestaciones. ${ }^{10}$

El folclor fue una excusa para poder comprender las relaciones socioculturales de otros grupos, como lo plantea Jacques Revel, quien resalta que se parte del concepto de folclor, para adentrarse en una reflexión sobre qué es y cómo se integra a lo popular, en qué contexto, cómo se desenvuelve y cuál es el papel de los actores sociales. Al considerar manifestaciones como la religión popular, los mitos, los rituales, las tradiciones y demás expresiones de la gente del pueblo, se pretendió encontrar elementos propios que caracterizaran las comunidades humanas, a dichas manifestaciones autores como Revel y Peter Burke denominaron "cultura popular". Así se hace referencia al concepto de cultura popular redescubierto por los franceses y al concepto de cultura popular que defienden los italianos ligado a la marginación, exclusión y subalternidad. ${ }^{11}$

Desde la folclorología, la reivindicación de lo popular se asoció a un movimiento nacionalista, que indagó por las expresiones culturales de la población, con miras a encontrar identidad a partir de las manifestaciones culturales que eran singulares y propias del pueblo. ${ }^{12}$

\footnotetext{
Ediciones Paidós Ibérica S.A., 2001) 18.

${ }^{9}$ Burke 22-23.

${ }^{10}$ Luis Ernesto Moreno Alaix, "Información folclórica", Pensamiento y Acción 34 (1969).

${ }^{11}$ Jacques Revel, Un momento historiográfico. 13 ensayos de historia social (Buenos Aires: Manantial, 2005) 104.

${ }^{12}$ Burke 58-60.
} 
Por su parte, el estudio de la cultura popular se inició en la década de los años 60 (Europa), momento en que historiadores provenientes del marxismo, entre ellos Antonio Gramsci, plantearon hacer un tipo de historia que reconociera las voces de otros actores sociales que habían permanecido en el anonimato o que eran invisibles ante los historiadores que realizaban la historia oficial. Así, se hizo referencia a un grupo social que Gramsci denominó "los subalternos". ${ }^{13}$ Se trató de una visión historiográfica que se contraponía a la tradicional mirada de actores sociales que se centraron básicamente en ver y estudiar el folclor, y una serie de actividades que tenían que ver con la tradición de sectores marginales y grupos sociales que no estaban en relación con las élites.

De manera particular, las dos tendencias predominantes, la folclorología y la cultura popular, establecen percepciones distintas sobre la cultura y la identidad del boyacense. Con relación a la primera, se caracterizaron géneros musicales, formas artísticas y comportamientos estéticos, lo cual le permitió a los boyacenses construir una idea de su propia cultura. Por su parte, están quienes planteaban que la identidad del boyacense se debería buscar en las expresiones y representaciones propias de los pueblos, es decir de los campesinos: de sus tradiciones, lenguaje y cotidianidad, a partir de la cultura popular.

De la tendencia sobre folklorología se puede aludir a escritores y políticos de la época, como Max Gómez Vergara, afiliado a la Academia de historia, desde donde hizo alusión a lo popular como expresiones folklóricas. Precisamente, en un texto sobre el municipio de Ventaquemada (Boyacá), se refiere explícitamente a la tradición como expresión del folclor y a la memoria histórica que generaron los grupos sociales sobre diversos eventos que son propios de las localidades. Este tipo de escritores, además de aludir a la grandeza de lo hispano y de ver cómo las culturas locales se fueron apropiando de estas expresiones foráneas, resalta igualmente cómo los pueblos han podido conservar estas tradiciones que las considera relevantes y parte sustancial de su identidad. ${ }^{14}$

La tendencia de la cultura popular se inspiró en la antropología cultural y retomó estudios como el de María Estela González sobre aspectos del habla popular boyacense, en el que se refería al multilingüismo territorial muisca y a sus dialectos, generados porque se entrecruzaron y mezclaron, haciendo posible una serie de divisiones o "jergas" que fueron asumidas en hablas regionales, locales y expresiones particulares. Resalta esta autora que en algunos casos los peninsulares omitieron la realidad del territorio conquistado y asignaron nombres a objetos, lugares y acciones desde la lengua ibérica, desconociendo las expresiones y representaciones de los nativos. Para el caso del altiplano cundiboyacense, lo muisca está presente en la onomástica del territorio, muchos apellidos fueron tomados de nombres o lugares

\footnotetext{
${ }^{13}$ Antonio Gramsci, ¿Qué es la cultura popular? (Valencia: Universidad de Valencia, 2011) 75.

${ }^{14}$ Max Gómez Vergara, "Cumplesiglos de Ventaquemada", Repertorio Boyacense Órgano de la Academia Boyacense de Historia, enero-junio (1978): 4416.
} 
indígenas, al igual que de prácticas cotidianas. ${ }^{15}$ Desde esta perspectiva, Luis Horacio López hizo alusión a la diferencia cultural y de manifestaciones existentes en Boyacá, a través de expresiones culturales diversas, prácticamente por regiones, lo que se puede apreciar a través de las comidas y canciones típicas, danzas específicas, indumentaria particular y en general en las diversas expresiones culturales y en la vida cotidiana de los pobladores. ${ }^{16}$ Por su parte, Luis Wiesner ${ }^{17}$ afirma que los pobladores de las zonas rurales del Departamento de Boyacá alcanzan a mantener una relación con la historia prehispánica y con las permanencias culturales propias de lo indígena.

Los aportes de estos estudiosos de la cultura se valieron de concepciones, metodologías y enfoques distintos para comprender expresiones de grupos subalternos, que se pueden hallar en el lenguaje y sus representaciones, en la cotidianidad, en las manifestaciones y en las tradiciones; por lo que con sus investigaciones dejaron un campo de análisis para comprender las manifestaciones culturales de grupos sociales hasta ahora invisibilizados, pero con un potencial de información ligado a la cotidianidad.

El estudio sobre la cultura de los boyacenses atrajo la atención del gobierno departamental, con miras a encontrar y caracterizar la identidad del boyacense. En esta dirección, se crearon dos instituciones: el Instituto Colombiano de Cultura y Bellas Artes de Boyacá (1975) y el Centro de Investigaciones de Cultura Popular, que pretendía aportar nuevos elementos a la tradición sobre folclor como parte de la construcción cultural. Mientras la tendencia enfocada a la cultura popular, que se basó en la investigación etnográfica, planteó una concepción más globalizante sobre la situación sociocultural.

La perspectiva institucional y la labor de los académicos fue bastante dinámica, por lo que se pretendió crear espacios para socializar manifestaciones culturales propias de la región, pero también para que la sociedad boyacense conociera expresiones culturales europeas, americanas y de otras regiones del mundo. En 1974, mediante el Decreto Departamental 047, bajo la dirección de Gustavo Mateus Cortés, se creó la Corporación de Promoción Cultural de Boyacá, con el fin de realizar actividades culturales, cívicas, turísticas y sociales. Este organismo sería el encargado

\footnotetext{
${ }^{15}$ María Estela González, "Algunos aspectos del habla popular boyacense”, Historia y Culturas Populares. Los estudios regionales en Boyacá, comp. Pablo Mora Calderón y Amado Guerrero Rincón (Tunja: Instituto de Cultura y Bellas Artes de Boyacá, Ministerio de Educación Nacional, Instituto Andino de Artes Populares, 1989) 181-188.

${ }^{16}$ Luis Horacio López Domínguez, "Historia y tendencias de las culturas populares en Boyacá", Historia y Culturas populares. Los estudios regionales en Boyacá, comp. Pablo Mora Calderón y Amado Guerrero Rincón (Tunja: Instituto de Cultura y Bellas Artes de Boyacá, Ministerio de Educación Nacional, Instituto Andino de Artes Populares, 1989) 145.

${ }^{17}$ Luis Wiesner Gracia, "Historia prehispánica y permanencias culturales", Historia y Culturas populares. Los estudios regionales en Boyacá, comp. Pablo Mora Calderón y Amado Guerrero Rincón (Tunja: Instituto de Cultura y Bellas Artes de Boyacá, Ministerio de Educación Nacional, Instituto Andino de Artes Populares, 1989) 101-102.
} 
de organizar anualmente el Festival Cultural de Tunja. ${ }^{18}$ De esta manera, la cultura como expresión de los pueblos empezó a ser incorporada en las políticas y acciones gubernamentales, por lo que pasó de la discusión a la acción y a la representación, a partir de programas de la administración municipal que pretendían proyectar a Tunja en el contexto nacional y regional, con eventos de interacción cultural que traspasaban el escenario de lo local.

Con miras a fortalecer las actividades culturales de la región, en 1975 se creó el Instituto de Bellas Artes de Boyacá, adscrito a la Secretaría de Educación, ${ }^{19}$ a la vez que se establece que algunos organismos deberían ser incorporados a esta instancia, por ejemplo: la Academia de Música de Boyacá, la Banda del Departamento, la División Cultural de Boyacá, la Casa de la cultura, el Museo de Museos y la Biblioteca Departamental Eduardo Torres Quintero. Desde allí se planteó que la cultura era una forma de posicionar a Boyacá en el contexto nacional e internacional, para generar un acercamiento a otras manifestaciones culturales y sociales nacionales e internacionales.

Desde 1977 Gustavo Mateus, siendo director del Instituto de Bellas Artes de Boyacá, instituyó el Festival Internacional de la Cultura, que reemplazó a la Semana de la Cultura Tunjana. Durante este lapso también se hicieron visibles algunas obras de infraestructura, como fueron la adecuación del teatro Móser y de la iglesia de San Ignacio para el desarrollo de conciertos; la creación del teatro infantil y el teatro municipal que sería la base para la creación de la Escuela Superior de Música. Estos proyectos se venían gestando desde la década de los años sesenta, como se puede apreciar en el sub-contrato para la construcción de la concha acústica en 1969. Según este sub-contrato, establecido entre el Departamento de Boyacá y el arquitecto Rogelio Morales, la concha acústica se convertiría en uno de los lugares más importantes para el desarrollo de conciertos y eventos culturales en la ciudad de Tunja. ${ }^{20}$

En las décadas de 1960 y 1970 se fortalecieron las actividades de tipo cultural, es así como se designaron salarios para los músicos de la Banda Sinfónica, ${ }^{21}$ a través de la Secretaría de Educación, como entidad encargada de las actividades culturales. Todos estos esfuerzos de la administración municipal estuvieron articulados con la visión que se quiso proyectar de Tunja como ciudad cultural, cuya labor se concentró en el lema: "Tunja cuna y taller de la libertad", que se extendió a los centros educativos. Así, la cultura empezó a tener protagonismo y por unos años centró la atención de gobernantes locales y departamentales, para designar recursos con miras a incentivar y fortalecer las expresiones artísticas y motivar la investigación sobre cultura popular.

\footnotetext{
${ }^{18}$ Rosa María Palencia Dotor, Historia de la escuela superior de música de Tunja. Años de esplendor musical en Boyacá (Tunja: Gobernación de Boyacá, Consejo Editorial de Autores Boyacenses, 2016) 61.

${ }^{19}$ Asamblea Departamental, Ordenanza No. 23 (1975).

${ }^{20}$ El Boyacense No. 3189, Sub-contrato entre el Departamento de Boyacá y el Arquitecto Rogelio Morales M., (Tunja, abril 10 de 1970). En el documento no se especifica ninguna fecha concreta de elaboración del contrato.

${ }^{21}$ El Boyacense No. 3360, Decreto 250 de 1969 (Tunja, 25 de febrero de 1974).
} 
A comienzos de los años ochenta se hicieron investigaciones que pretendieron analizar las costumbres, tradiciones y expresiones culturales de los campesinos. Desde el punto de vista gubernamental se planteó un interés por crear más escuelas, más instituciones, más entidades. Se realizaron estudios sobre la vivienda rural tradicional, como la del Valle Tenza, que, bajo la dirección de Alberto Mendoza, hizo alusión a la necesidad de cambio en el tipo de viviendas, por el uso de materiales para la construcción, técnicas y diseños, particularmente por el uso de los espacios. Así, durante este lapso se pudo apreciar cambios sustanciales en el uso de materiales nativos, ya que el campesino tenía sus propias propuestas de cómo organizar y distribuir el espacio, y de qué tipo de materiales utilizar, lo cual incidió considerablemente en el prototipo de vivienda campesina, asociando esta transformación al proceso de modernización en infraestructura. ${ }^{22}$

Posteriormente, se produjo una tensión fuerte entre tradición y modernización, que tuvo implicaciones sustanciales en el nivel de vida de los campesinos, generándose nuevos valores evidenciados en la vida cotidiana de los sujetos, transformando la cultura de la ruana y el sombrero, que se había vislumbrado como prototipo de la cultura del boyacense y que se reflejaba en espacios de interacción, como la plaza de Bolívar o la plaza de mercado.

Las investigaciones sobre cultura popular asumieron nuevos retos para intentar comprender la región como espacio de interacción social, económica y, obviamente, cultural; generando otras interpretaciones sobre las particularidades, las identidades y la pretensión de articulación en torno a lo nacional. Al respecto, Luis Wiesner sostiene que el significado de "región", planteado desde la Antropología, se refiere a la conciencia que los hombres tienen sobre sus procesos y a la apropiación que hacen de su entorno social en la práctica de su vida cotidiana. Esto motiva a estudiar los procesos históricos vividos por cada comunidad, estableciendo sus particularidades y especificidades, y analizando las diferencias. ${ }^{23}$ De esta forma, la presente propuesta de análisis entra en contradicción con las perspectivas de historia regional centrada en la cultura dominante, que es vista y representada por las élites, y que puede estar en oposición con las vivencias de la cotidianidad de los de abajo.

\section{Folclor e identidad regional}

La pretensión de la investigación que soporta este escrito era tratar de establecer, en la relación con la dimensión histórico-cultural nacional, la existencia de una conciencia regional boyacensista, ¿cómo lograrla?, ¿se podrían retomar elementos desde las glorias independentistas?, ¿desde las historias?, ¿desde las artes?, ¿desde la literatura?, ¿desde la cultura?, ¿desde el turismo? Para determinar si existía esa interacción se consideró pertinente analizar rasgos característicos propios, así como

\footnotetext{
${ }^{22}$ López Domínguez 150-151.

${ }^{23}$ Wiesner 128.
} 
patrones culturales regionales. Para lograrlo, se hacía necesario conocer el territorio y la estructura geográfica. Otro aspecto que se resaltó fue la identidad étnica, donde se consideraron diferentes elementos raciales que conformaron el pueblo boyacense: indígena (representación del chibcha o muisca) y el español.

En el caso del Departamento de Boyacá se centró la atención en la formación étnico-cultural, relacionada con las expresiones y representaciones, y la historia de los pueblos; asimismo en las vigencias: costumbres, tradiciones, usos cotidianos, creencias y el folclor, que le ofrecían tipicidad y autenticidad a los habitantes. ${ }^{24}$ Justamente, el concepto de folclor lo utilizaron, en los años sesenta y setenta en Colombia, algunos estudiosos sobre la cultura, para tratar de comprender la relación entre expresión cultural de los pueblos y sus manifestaciones, a través de la música, el arte, la vida cotidiana y en general las formas de expresión de los grupos o sectores populares.

Una pregunta central fue cómo encontrar la diferencia cultural del boyacense frente a la cultura cundinamarquesa o santandereana, es decir ¿qué diferenciaba al boyacense del habitante de otras regiones? La interpretación de esta perspectiva sugiere un análisis funcionalista, en el que se consideró a las partes como fundamento para la comprensión del todo como un engranaje, a la vez que el conjunto no se concebía sin las partes. Sin embargo, desde este punto de vista, es importante ver que las regiones también fueron vistas como unidades suficientes de identidad, lo cual las hacía particulares. Se asumió que la región se identifica y se conforma desde lo étnico-cultural, en sus costumbres, tradiciones, vigencias, usos cotidianos y folclor, que le proporcionan una especificidad y autenticidad.

El estudio de la identidad cultural del boyacense se inició entorno a la música, los cantos, las danzas e instrumentos musicales. Según Javier Ocampo López, la cultura boyacense tiene raíces chibchas y españolas, que se han transmitido de generación en generación. Los indígenas utilizaban los cantos para la siembra, para realizar todo tipo de trabajo que consideraban central y para la integración de la comunidad, donde las danzas y los cantos eran imprescindibles en todas las fiestas religiosas y sociales, en los sacrificios al sol, las fiestas de las cosechas y regocijos públicos. ${ }^{25}$ Los indígenas, al parecer, elaboraban sus propios instrumentos musicales que utilizaban en las ceremonias y que daban una tonalidad particular. Estos instrumentos, junto con los aportados por los españoles, construyeron campos interpretativos diferentes, que igualmente tenían que ver con los materiales utilizados para la elaboración de los mismos.

Los investigadores sobre cultura popular coinciden en resaltar que lo cultural ha sufrido un proceso de hibridación o articulación, generando nuevas expresiones musicales y dancísticas con representaciones particulares, en las que se

\footnotetext{
${ }^{24}$ Ocampo López, Los fundamentos históricos 128.

25 Javier Ocampo López, "Música, bailes y cantos nativos", El Lector Boyacense, ed. Vicente Landino Castro (Tunja: Ediciones la Rana y el Águila, 1980, tomo II) 736-737.
} 
puede apreciar lo indígena y lo hispano, incluso lo "afro"; y que al mezclarse han consolidado expresiones culturales que se han afianzado en ciertas regiones. Por ejemplo, las músicas populares registradas del territorio boyacense reflejan una profunda interacción de sus sistemas, conjugan: joropo, guabina, bambuco y pasillo, y utilizan instrumentos particulares y formas de danzar diferentes a otras regiones como Santander o Cundinamarca.

Quienes estudiaron la cultura desde la perspectiva del folclor pretendieron encontrar en la música y la danza características propias de los boyacenses. En cuanto a la música intentaron caracterizar los instrumentos, la interpretación y las técnicas musicales, al respecto resaltaron que el bambuco como género instrumental tuvo una mayor aceptación entre los músicos populares y que posteriormente se desarrolló a través de géneros musicales como la rumba criolla, que aún pervive en las prácticas musicales que se cultivan en las áreas rurales. ${ }^{26}$ Sin embargo, dichas prácticas requieren un trabajo más sistemático, en el sentido de conocer: tonalidad, organología, color del sonido (estética) y armonía musical, para determinar las permanencias de lo indígena, la influencia española y la construcción de prácticas musicales a partir de la hibridación, que constituyen expresiones musicales y particulares propias.

Así, la mezcla o sincretismo cultural fomentó una hibridación cultural que dio origen a otros géneros musicales. Los indígenas utilizaron flautas, trompetas de caracol de diversos tamaños y ocarinas, además de maracas, sonajeros y conchas, también utilizadas en las ceremonias religiosas. ${ }^{27}$ Por otra parte, los españoles introdujeron la guitarra, a partir de la cual aparecen como apropiaciones particulares la bandola y el tiple. Este último es considerado como el instrumento nacional en Colombia, cuya existencia en el país data de $1791 .{ }^{28}$ El tiple se convirtió en uno de los instrumentos folclóricos más importantes de uso de los boyacenses, y junto con la guitarra son instrumentos fundamentales en las interpretaciones musicales que realizan. ${ }^{29}$

Con los antes mencionados instrumentos de cuerda pulsada, según Ocampo, se interpretaron géneros musicales ligados a la danza, tales como la chirimía, el torbellino, la guabina, el bambuco y el pasillo. El torbellino se convirtió en uno de los géneros musicales y de danza más importante y representativo de la región, siendo involucrado en las romerías y fiestas patronales. ${ }^{30}$ Aunque el autor citado, Ocampo López, no refiere fuentes, se ha convertido en una autoridad para hablar de la cultura y básicamente del folclor de los boyacenses, así como de los instrumentos musicales, sus sonidos y la forma como fueron utilizados por los indígenas y los campesinos,

\footnotetext{
${ }^{26}$ Carlos Rojas Hernández, "Sobre la regionalización en los estudios musicológicos”, 193-194.

27 Véase piezas arqueológicas expuestas en el Museo Arqueológico de la Universidad Pedagógica y Tecnológica de Colombia, Tunja.

${ }^{28}$ María Eugenia Londoño y Alejandro Tobón, "Bandola, tiple y guitarra: de las fiestas populares a la música de cámara", Artes, la Revista 7, 4 (2004) 46.

${ }^{29}$ Ocampo López, Música, bailes y cantos 739.

${ }^{30}$ Ocampo López, Música, bailes y cantos 740-741.
} 
siendo su documento una fuente documental de gran relevancia para el estudio de la cultura popular. De esta manera podemos apreciar cómo las expresiones culturales populares fueron un objeto de estudio para investigadores como Javier Ocampo, Horacio López, Jaime Jaramillo Uribe y Germán Colmenares, entre otros, quienes centraron su atención en tratar de establecer las características, no solamente de la cultura de las élites, sino también de otros sectores sociales como el caso de los chibchas $^{31}$ y de los campesinos, sus tradiciones y expresiones culturales.

En esa articulación entre los intelectuales y la administración pública se proyectaron acciones para indagar por la identidad del boyacense, con miras a establecer características propias, a visibilizar sus expresiones y a fortalecer dichas manifestaciones. En ese sentido, además de las investigaciones a las que se ha hecho referencia, también se proyectó publicar libros académicos y de texto que consiguieran llegar a todo tipo de público, incluyendo las instituciones educativas, para motivar a los estudiantes a reconocer y fortalecer sus expresiones culturales, pero también a conocer expresiones culturales foráneas, este fue el caso de la música y la danza que se enseñaron en la Academia de Música, los invitados del Festival Internacional de Cultura, organizado por el Instituto de Cultura y Bellas Artes de Boyacá (ICBA), institución que hizo parte, en los años setenta, de todo un proyecto cultural para reivindicar la cultura boyacense.

En ese orden de ideas, se publicaron libros como El lector boyacense que pretendió ser un espacio para difundir las representaciones literarias más importantes, incluyendo leyendas y mitos escritos por boyacenses para un público regional y nacional. El objetivo de esta publicación era dar a conocer el pasado de los boyacenses, la belleza de sus paisajes naturales, el orden socio-económico, político, religioso, las costumbres, las tradiciones y el folclor. Las investigaciones se inspiraron en una teoría cíclica, en la que las regiones fueron presentadas como fuerzas internas que podrían llevar a la unidad del mundo socio-cultural. Así, los científicos sociales, inspirados en la teoría funcionalista, pretendieron explicar la sociedad como un engranaje de partes. En este mismo libro se presenta el texto "El arte, la música, el folclor y la jocosidad en Boyacá" de Antonio Martínez Zulaica, quién, centrándose en las artes plásticas de Boyacá, analizó la relación entre el hombre y el paisaje, aludiendo a cómo lo natural hace parte de la expresión cultural y cómo los grupos humanos utilizan el paisaje como su hábitat. En el mencionado escrito se percibe diversidad de expresiones culturales, es decir, para Martínez Zulaica un pueblo es un repertorio de costumbres. ${ }^{32}$

\footnotetext{
${ }^{31}$ El grupo de intelectuales mencionado se referían a los indígenas del altiplano como Chibchas y no Muiscas. Las investigaciones antropológicas se refieren en general a la cultura que habitaba el altiplano cundiboyacense. Dichas referencias se cambiaron cuando los antropólogos, en la década de los años setenta, analizaron las particularidades de la organización política, social y económica, de la lengua, la producción y las manifestaciones de los grupos humanos que habitaron el altiplano y allí establecieron diversidades de lenguajes, entonces grupos étinico-culturales diversos. Uno de estos grupos era el de los muiscas, que hablaban la lengua chibcha. Entrevista a Blanca Acuña sobre el trabajo del Museo Arqueológico de Tunja, a partir de las excavaciones realizadas y de los estudios arqueológicos, antropológicos e históricos de los grupos del altiplano (Tunja, junio 15 de 2017).

${ }^{32}$ Antonio Martínez Zulaica, "El paisaje y el hombre boyacense”, Pensamiento y Acción 1 (1978) 17-19.
} 
Según Ocampo López, el texto "El Lector Boyacense" pretendió formar una nueva mentalidad del hombre boyacense, para tratar de consolidar la visión del boyacense como el personaje que indaga sobre su pasado, experiencias y procesos, y busca soluciones a sus problemas, con la creación de modelos propios adaptables a su realidad histórico-temporal regional y nacional, pensando en el progreso ascendente en relación con el desarrollo integral de Colombia y América Latina. ${ }^{33}$

En la década de los años setenta, la enseñanza musical se consideró un escenario muy importante para promover la cultura en Tunja, con prototipos culturales europeos evidenciados en las clases de interpretación instrumental, zarzuela u ópera ofertados en el Conservatorio de Música, donde se matriculaban principalmente los hijos de las élites tunjanas que tenían ciertas condiciones económicas y que podían pagar los cursos y comprar los instrumentos musicales. Las clases se impartían en el Conservatorio que venía funcionando desde 1910, donde se encontraban niños y jóvenes que además de su formación escolar querían desarrollar otras habilidades y acercarse a la "cultura", que no estaba al servicio de todos los sectores de la sociedad. Como lo sugiere Rosa María Palencia, Enrique Medina Flores sería uno de los mayores defensores de la música, como parte de la "cultura" de élite, que pretendía acercar a la sociedad boyacense a los grandes escenarios de expresión cultural europea. Por lo cual la década de 1960 fue muy importante porque se creó la Academia de Música de Tunja, de la que fue director Guillermo Amezquita Nossa, ${ }^{34}$ y que posteriormente dio origen a la Academia de Música de Boyacá.

Desde 1973 la Academia de Música de Boyacá quedó adscrita al ICBA y estuvo dirigida por varios maestros de talla internacional. Esta institución ofrecía cursos a niños, jóvenes, amas de casa y otras personas interesadas. Dentro de la oferta académica estaban cursos de: solfeo, gramática musical, canto, coro, instrumento (guitarra, piano, violín, contrabajo), armonía, teoría, historia de la música, folclor, iniciación musical, danzas y conjunto instrumental. ${ }^{35}$ Se puede apreciar la tendencia de hacer extensiva la cultura, y particularmente la música de academia, a los sectores diversos de la sociedad, introduciéndolos en el mundo de la música clásica con las interpretaciones musicales y formándolos en el manejo de los instrumentos, tonalidades, gramática e instrumentalización, siempre bajo los cánones de la tradición musical centroeuropea. Así, podríamos percibir que con la Escuela de Música de Boyacá se inició otra etapa en la cultura, pues además de buscar espacios de interacción cultural se pretendió imponer la cultura foránea desde la educación musical. De igual forma, sucedió con la iniciativa del Festival Internacional de la Cultura, que apostaba por la difusión de la música clásica a partir de interpretaciones musicales de la más alta calidad técnica, con invitados internacionales y la inauguración, cada año, de la entonces Sinfónica Nacional de Colombia.

\footnotetext{
${ }_{33}$ Javier Ocampo López, "La identidad del pueblo boyacense", El Lector Boyacense, ed. Vicente Landines Castro (Tunja: Ediciones la Rana y el Águila, Tomo I, 1979), 1- 11.

${ }^{34}$ Palencia 28-32.

${ }^{35}$ Palencia 79-80.
} 
Desde otra perspectiva, se encontraba la interpretación musical de los grupos campesinos, que conservaban expresiones tradicionales muiscas, articuladas con estéticas y organología hispana, cuya hibridación había dado origen a otros géneros musicales propios de la región del altiplano cundiboyacense, pero que aún no se consideraban propios para fomentar su aprendizaje. Precisamente ésta sería la tarea de la Escuela de Música a finales de los años setenta y comienzos de los ochenta, donde se retomaron los saberes populares de la música en la academia, con la división Escuela Especializada en Música y Danzas Populares, dependencia, creada en la década de 1980, como una dependencia del ICBA. De allí se derivó el aprendizaje de los ritmos, los versos, la interpretación y la tonalidad, pero bajo la dirección de un experto en el arte, que ponía en juego su saber para lograr otra armonía de instrumentos, voces, cuerdas y, en general, de la interpretación musical.

Simultánea a la música de academia emergía otra tendencia musical que a partir de investigaciones sobre los saberes y expresiones populares inspiraron un grupo musical que visibilizó las expresiones populares de los boyacenses y se asumió como parte de la identidad cultural, nos referimos a la carranga.

\section{La carranga como expresión de la música popular e identidad del boyacense}

El escenario de los años setenta, cuando se generan propuestas ideológicas desde el socialismo y comunismo, motiva a cuestionar prácticas y contextos de la política tradicional, que son entendidas por algunos folclorólogos como maquinarias devastadoras de la cultura popular ${ }^{36}$. Es el contexto en el que Jorge Velosa, ${ }^{37}$ líder de la carranga, está inmerso, entonces acude a los versos, a la poesía y a la música para denunciar, y para reconfigurar la cultura tradicional de los boyacenses.

Según José Alexander Garzón, ${ }^{38}$ citando a Ponce, resalta que el término carranguero se asocia con comerciantes de carne proveniente de animales muertos y en ocasiones en estado de descomposición. Por su parte, Claudia Sierra, citada por Darwin Ávila, señala que el término carranguero se refiere a animal muerto y que se denominaba "el carranguero" a aquel personaje que comercializaba la carne de estos animales, en algunos casos en estado de descomposición. ${ }^{39}$ Para Jorge Velosa, la carranga es libertad, "...la carranga es lo que yo siento y es mi forma de vivir, es una manera de ver e interpretar la vida", ${ }^{40}$ cuya característica fue el

\footnotetext{
${ }^{36}$ Carlos Miñana Blasco, "Entre el folklore y la etnomusicología. 60 años de estudios sobre la música popular tradicional en Colombia”, A Contratiempo. Revista de música en la cultura 11 (2000): 37.

${ }^{37}$ Nacido en Ráquira (Boyacá), el 6 de octubre de 1949.

38 José Alexander Garzón Cano, "Características interpretativas de la música carranguera" (Trabajo de Grado, Maestro en Música, Universidad de Cundinamarca, 2017) 26.

39 Darwin Rodrigo Ávila Torres, "De campesinos y carrangueros. Representaciones del Campesinado cundiboyacense 1976- 1990” (Tesis, Maestría en Historia, Universidad Javeriana, 2018) 69-70.

${ }^{40}$ Velosa y Los Carrangueros, "Clase Carranguera-Jorge Velosa. Universidad Jorge Tadeo Lozano 2", Bogotá, 20 de diciembre de 2009 [videoconferencia],http://www.youtube.com/watch?v=KzmGAjC3URQ (21/02/2018)
} 
humor, la espontaneidad, el sentido social y la reivindicación de un grupo social con características culturales propias.

Según José Alexander Garzón, Velosa retoma el concepto para representar a la cultura campesina boyacense que estaba próxima a morir y desaparecer. En ese contexto Jorge Velosa, como estudiante de veterinaria en la Universidad Nacional de Colombia, conoce a Javier Moreno estudiante de Arquitectura, quien también se sentía identificado con la música popular. Posteriormente se vinculan Javier Arráez que interpreta el tiple y Ramiro Zambrano la guitarra, este fue el origen de uno de los primeros grupos musicales con reconocimiento nacional e internacional, lo que no significa que no hubiera en las regiones boyacenses intérpretes de música popular.

Darwin Ávila ubica la música carranguera como música social, dentro de la tendencia folclórica con un sentido social importante, porque se pretendió representar la cotidianidad del campesino, a la manera de un "arte costumbrista" caracterizado por el uso del lenguaje en una forma coloquial, junto con unos ritmos, instrumentos y trajes típicos de los campesinos o habitantes rurales. ${ }^{41}$ Este autor afirma que la carranga apareció en Colombia entre 1976 y 1989, con miras a representar socialmente al campesino, su cotidianidad, su trabajo y sus luchas. Además de resaltar el traje del campesino boyacense, se hace alusión a sus expresiones como sujeto social, especialmente la humildad y la sencillez. Es así como se consolida el grupo musical Los Carrangueros de Ráquira, en 1977 en la Universidad Nacional de Colombia, ligado a la música de protesta, pero con la pretensión de reivindicar al campesino y sus luchas. Con este propósito, los artistas aprovechan la invitación al programa "Canta el Pueblo" de radio Furatena de Chiquinquirá, para hacer un programa radial a partir de los temas que enviaban los vecinos de las veredas de Chiquinquirá y Ubaté, además de dialogar con los campesinos que se comunicaban, expresando sus necesidades, tradiciones y pretensiones. De esta experiencia recogieron saberes populares en torno a la música, a la vez que mostraron ritmos campesinos autóctonos, con temáticas que aportaban y con las cuales la principal audiencia, las personas campesinas, se sentían identificadas. ${ }^{42}$ Posteriormente, se definió el traje y la indumentaria para representar adecuadamente a esta población rural.

La música carranguera empezó a describir situaciones de la vida cotidiana de los campesinos, actividades, eventos y circunstancias particulares, en que se podía apreciar la alegría, humildad y espontaneidad de la gente nativa del sector rural. ${ }^{43}$ Esta también fue una forma de crítica a la cultura de la élite, pero también un espacio para visibilizar a estos sectores populares con sus diversas manifestaciones. Así, la producción musical de este género ha retomado ritmos, estilos y temas, que inicialmente estaban dirigidos a los habitantes del campo, pero rápidamente los ritmos fueron escuchados en varios

\footnotetext{
${ }^{41}$ Ávila Torres 54.

${ }^{42}$ Fundación Corazón Carranguero, "Entrevista a Ramiro Zambrano partes 1, 2, 3, 4, 5 y 6", Bogotá, 10 de abril de 2018 [videoconferencia],https://www.youtube.com/watch?v=Fg_Z1KWK5HQ (15/05/2018)

43 Tomás Sánchez Amaya y Alejandro Acosta Ayerbe, "Música popular campesina, usos sociales, incursión en escenarios escolares y apropiación por los niños y niñas: la propuesta musical de Velosa y los Carrangueros", Revista Latinoamericana de Ciencias Sociales 6, 1 (2008) 120.
} 
escenarios. De esta manera, Los Carrangueros de Ráquira fue una de las primeras agrupaciones en visibilizar las culturas populares a través de la música, los vestidos, los dichos, el lenguaje y el baile típico, como expresión cultural del boyacense.

La música carranguera empezó a ser escuchadas y reproducida en varias regiones del país, y mientras Los Carrangueros de Ráquira se posicionaban como intérpretes de la cultura popular boyacense, otros grupos musicales como los hermanos Torres, de San Gil, también buscaron mecanismos para hacerse visibles como representantes de las culturas populares de la región. Es así como se empezaron a representar otros eventos de estos grupos sociales, como la llegada de campesinos a las ciudades y la forma como asumían su rol de habitantes citadinos. Hacia 1982 se unieron Jorge Velosa y los Hermanos Torres con el fin de continuar el proyecto de interpretación de la música popular, en torno a la consolidación del hasta entonces nuevo género musical, la carranga.

En términos musicales, en relación con los ritmos que convergen en la carranga, Ramiro Zambrano, uno de los integrantes de Los Carrangueros de Ráquira, sostiene que en la interpretación musical se retomó la rumba criolla, que fue un estilo musical que combinó el formato de banda con elementos tomados de ritmos cubanos, caribeños y costeños, que le dieron otra estilística a la música popular, a la vez que influyó en el tipo de baile, convirtiéndola en música más festiva y alegre. ${ }^{44}$ Por su parte, Jorge Velosa resalta que la música carranguera introdujo elementos de la rumba criolla y del vallenato, que le dieron una expresividad particular. Después recibieron influencias de Guillermo Buitrago, con rumbas y merengues, aportando estas músicas el toque de alegría y expresividad a la interpretación de la carranga. ${ }^{45}$ Así, podríamos señalar que en la década de los años setenta mientras las élites escuchaban música de cámara (zarzuelas y óperas), las clases populares escuchaban torbellinos, guabinas y pasillos, coplas, romances y rumbas criollas.

De la labor de Los Carrangueros de Ráquira, y posteriormente de Jorge Velosa y los Hermanos Torres, emergieron otras producciones y agrupaciones musicales como "Los Hermanos Amado", de Chíquiza, Boyacá, Colombia, en 1987, y "Los Filipichines" creado en 1988, que, aunque tenían tradición de intérpretes, solamente años más tarde adquieren reconocimiento nacional. En la década de los años ochenta igualmente emergió otro grupo musical, "Los Jeroces", que igualmente es asociado con un nuevo género denominado "guascarrilera", que retomó, como influencia, el merengue vallenato interpretado por Guillermo Buitrago, y desde su interpretación musical pretendieron representar al campesino boyacense que migró a las ciudades. Estas agrupaciones, además de incorporarse en el mundo laboral de la interpretación musical, mantenían cierta identidad con su región. Renato Paone ${ }^{46}$

\footnotetext{
${ }^{44}$ Garzón Cano 28.

${ }^{45}$ Canal Cosmovisión, "Jorge Velosa nos cuenta de su música”, 16 de abril de 2015 [videoconferencia], https://www.youtube.com/watch?v=QMqpd8Kz-G8\&t=46s (15/05/2018)

${ }^{46}$ Renato Paone, "La música carranguera" (Trabajo de Grado, Estudios de Música, Escuela Popular de Arte, 1999) 56.
} 
resalta que el surgimiento del término "Guasca" es usado para denominar a las personas desplazadas del campo a la ciudad y que además el término refiere a ordinariez, a la vez que se asocia a una forma de envoltura de paquetes con guasca (corteza del árbol de plátano). La música "carrilera" tiene que ver con las expresiones culturales que se consolidaron a partir del ferrocarril como medio de transporte, tanto desde el punto de vista comercial, de circulación de géneros musicales, como de tecnologías. De esa forma, se puede plantear que el concepto "guasca" representa la migración campesina a las áreas urbanas, por lo que ha tenido que asimilar otras expresiones culturales, otras formas de vida y reconfigurar sus imaginarios, donde "guascarrilera" busca representar esa "hibridación cultural", en términos de Canclini.

El merengue y la rumba criolla parecen ser dos componentes fundamentales de la música carranguera, los que se interpretan con cuatro instrumentos musicales: Requinto, Tiple, Guitarra y Guacharaca ${ }^{47}$ A esta música le insertaron un estilo alegre, dinámico y expresivo, que motiva los movimientos de los pies reflejados en el baile. Con relación a los instrumentos:

La guacharaca es un instrumento indígena tradicional en las músicas andinas [...] y cuya ejecución en la carranga es igual a la del torbellino, cumpliendo un papel percutivo. El tiple, instrumento de 12 cuerdas, era utilizado tradicionalmente en la interpretación del bambuco y del pasillo y se caracteriza por ser uno de los pocos que puede hacer melodías y armonías simultáneamente [...] El requinto, que también posee 12 cuerdas y que tradicionalmente se ha usado para la interpretación de bambucos, guabinas, torbellinos y pasillos, entona las melodías y hace solos. La guitarra, es un instrumento español y fue introducida en las músicas campesinas con la función de interpretar los bajos o bordones. ${ }^{48}$

Tanto los instrumentos como la expresividad y el baile han sido adoptados por los campesinos y gentes del altiplano cundiboyacense, y han sido considerados como manifestaciones festivas. En este sentido ha habido apropiación de la música carranguera como expresión de la cultura del pueblo. ${ }^{49}$

El paso de Los Carrangueros de Ráquira a convertirse en un grupo musical reconocido fue motivado por el puertorriqueño Ricardo Acosta, quien los convenció de realizar una producción musical. Fue así como se consiguió trascender los límites del escenario para que un mayor número de campesinos se sintiera identificado. ${ }^{50}$ Según Darwin Ávila, la música carranguera retomó la representación del campesino y se convirtió en una especie de denuncia social con sus temáticas, pero visualmente también representó sus expresiones, a través del vestido y el lenguaje ${ }^{51}$.

\footnotetext{
${ }^{47}$ Paone 71.

${ }^{48}$ Nicole Ocampo Hernández, "Las músicas campesinas carrangueras en la construcción de un territorio", (Tesis, Maestría en Patrimonio Cultural y Territorio, Universidad Javeriana, 2014) 7.

${ }^{49}$ Jaime Araque, "Visibilización y difusión de la música tradicional campesina en Boyacá y la región, como herramienta de paz", Revista Principia Iuris 22 (2014): 41.

${ }^{50}$ Fundación Corazón Carranguero.

${ }^{51}$ Ávila Torres 99.
} 
A través de la música carranguera y los contenidos en las letras se mostró la cotidianidad del campesino, tal vez de las tradiciones no conocidas, omitidas, olvidadas o silenciadas. Así Jorge Velosa y sus agrupaciones le dieron voz a estos grupos subalternos invisibilizados. Esto permitió que la población del área rural de Boyacá, Cundinamarca y Santander se sintiera identificada con la letra, la música y los ritmos. Otro componente central fue el escenario y la forma como éste fue apropiado tanto por Los Carrangueros y demás grupos musicales, como por los campesinos y la nueva forma de ser visibilizados, porque sintieron que la música expresaba su dialecto, cotidianidad y en general sus manifestaciones. Fue una forma de reivindicar la cultura campesina frente a la representación peyorativa que hacían las élites al describirlos como atrasados, incultos e incivilizados.

Aunque la temática central fue la denuncia y reivindicación de la cultura campesina no fue solamente este sector el punto de interés de Los Carrangueros de Ráquira. En sus inicios la canción social también abordó otras temáticas, como se puede apreciar en la canción la "Lora proletaria", que se convirtió en un himno de la lucha del pueblo, que aunque aparece publicada en 2010, da cuenta de denuncias sociales que planteaban los movimientos estudiantiles que se debatían en los años setenta. ${ }^{52}$ En otras expresiones musicales como "El campesino embejucao" o "La papa de la carranga", se aprecian igualmente denuncias sobre la situación del campesino y de la población rural en general.

La representación del campesino, de sus labores y expresiones se puede apreciar a través de la interpretación jocosa y de doble sentido, que son manifestaciones de la cultura popular de los campesinos boyacenses, como se pueden evidenciar en la música carranguera; por lo que se convirtió esta música en una forma de representación social y cultural, que en la combinación de ritmos y tonalidades, narra y recrea vivencias y sentimientos de esta porción de la población. Así sus ritmos, además de la denuncia, representación y narración, divierten y recrean escenarios particulares con los que los campesinos y la cultura popular boyacense se identificó y se sigue identificando. Al respecto, Marisol Rojas ${ }^{53}$ resalta que la música carranguera además de referir amores, despechos, el cariño por los animales y otras historias del diario vivir, permite apreciar los contrastes entre la cultura rural y urbana, particularmente caracterizando cómo los habitantes del ámbito rural se tienen que enfrentar a la "modernidad" y resultan inmersos en ésta; pero también cómo son vistos por los citadinos, como personajes extraños y "atrasados".

\section{Conclusiones}

En la década de los años ochenta del siglo XX, en el Departamento de Boyacá, un grupo de intelectuales se dieron a la tarea de indagar por la identidad del boyacense, para intentar caracterizar sus expresiones culturales y adicionalmente fomentar la

\footnotetext{
52 Jorge Velosa, La lora Proletaria [en línea] (9 de abril de 2018), https://www.youtube.com/ watch?v=nTdJniLXVxU (15/05/2018)

${ }^{53}$ Francy Marizol Rojas Parra, "La carranga como escenario vivo de la tradición e identidad cultural local y regional del Departamento de Boyacá”, UNAD 12 (2013) 189.
} 
formación musical y en artes plásticas, aspecto que se consideró fundamental para proyectar a Boyacá como región cultural. En esas reflexiones se pudo establecer dos tendencias, quienes defendieron la idea de formar cultura a partir de expresiones musicales y artísticas de academia, y la otra que pretendió indagar por las expresiones propias de los pueblos para conocer rasgos particulares y formas de expresión cultural. En ese orden de ideas se percibió la tendencia de la folclorología, que además de reivindicar lo hispano como eje fundamental de la formación cultural del boyacense, promovió la creación de instituciones tales como la Academia de Música, el Instituto de Cultura y Bellas Artes de Boyacá y el Festival Internacional de la Cultura, con miras a promover la formación cultural del boyacense. Desde otra perspectiva, la incursión de la antropología en la indagación sobre la cultura boyacense trajo consigo investigaciones que iban más allá de la música y las artes plásticas, para centrarse en los mitos, la cultura religiosa, la cotidianidad y las tradiciones más cercanas a la cultura popular. El propósito común de las dos tendencias era indagar por la identidad del boyacense.

Las reflexiones sobre estas temáticas llevaron consigo un estudio sistemático de la cultura, que pretendió encontrar características fundamentales en la población boyacense y establecer mecanismos de interacción a través de eventos como el Festival Internacional de la Cultura. El principal propósito era proyectar a Boyacá como un departamento con potencial cultural, ya desde la academia o desde la reivindicación de la música y las artes plásticas. Este objetivo implicó una necesaria articulación con la administración pública, que a su vez designó recursos para el desarrollo y fortalecimiento de actividades culturales, con miras a indagar y analizar la identidad del boyacense. Por otra parte, el esfuerzo por fortalecer la Academia de Música, para motivar la formación de expertos e intérpretes de instrumentos musicales con altas calidades técnicas, también fue una fortaleza para el conocimiento de una cultura foránea; sin embargo, no fue esta la que permitió conocer y caracterizar la cultura boyacense. Como se podrá apreciar, el pueblo boyacense, no solamente campesinos, sino citadinos y en general población del altiplano cundiboyacense se identificaron con el género musical emergente a finales de la década de 1970, consolidado por Jorge Velosa y Los Carrangueros de Ráquira, quienes, con sus ritmos, dichos, vestuario, lenguaje y melodías popularizaron las acciones de los campesinos y de la gente del común, y de esta manera hicieron manifiesta una cultura tradicional que estaba próxima a desaparecer.

Los campesinos y población boyacense se identificaron más con la música carranguera porque en ella vieron expresiones del lenguaje, de su cotidianidad y de sus manifestaciones, acercándolos a reconocer sus vivencias y necesidades. Además, el sentido alegre que se retomó de la rumba criolla y del vallenato se incorporó en las fiestas, en la cotidianidad, hasta convertirse en un género musical que aun hoy día caracteriza a los sectores populares del altiplano cundiboyacense. 


\section{Bibliografía}

\section{Fuentes Primarias}

Decreto 250 de 1969. El Boyacense No. 3360 (Tunja, 25 de febrero de 1974).

Ordenanza No. 23 (1975). Asamblea Departamental.

Sub-contrato entre el Departamento de Boyacá y el Arquitecto Rogelio Morales. El Boyacense No. 3189 (Tunja, 10 de abril de 1970).

Carlos Rojas Hernández, "Sobre la regionalización en los estudios musicológicos", 193-194.

\section{Fuentes de archivo}

Museo Arqueológico de la Universidad Pedagógica y Tecnológica de Colombia, Tunja.

\section{Entrevistas}

Acuña, Blanca, entrevista realizada por Ruth Nayibe Cárdenas. Tunja, 15 de junio de 2017.

\section{Fuentes secundarias}

\section{Libros}

Burke, Peter. La cultura popular en la Europa Moderna. Madrid: Alianza, 1991.

García Canclini, Néstor. Culturas hibridas. Estrategias para entrar y salir de la modernidad. Barcelona: Ediciones Paidós Ibérica S.A., 2001.

Gramsci, Antonio. ¿Qué es la cultura popular? Valencia, Universidad de Valencia, 2011.

Guinzburg, Carlo. El queso y los gusanos, el cosmos según un molinero del siglo XVI. Barcelona: Ediciones Península, 1981.

Ocampo López, Javier. Música y Folclor de Colombia. Bogotá: Plaza y Janés Editores, 2004.

Palencia Dotor, Rosa María. Historia de la escuela superior de música de Tunja. Años de esplendor musical en Boyacá. Tunja: Gobernación de Boyacá, Consejo Editorial de Autores Boyacenses, 2016.

Revel, Jacques. Un momento historiográfico. 13 ensayos de historia social. Buenos Aires: Manantial, 2005. 
Silva, Renán. República Liberal, intelectuales y Cultura Popular. Medellín: La Carreta Editores, 2012.

\section{Capítulos de libros}

González, María Estela. "Algunos aspectos del habla popular boyacense". Historia y Culturas Populares. Los estudios regionales en Boyacá. Comp. Pablo Mora Calderón y Amado Guerrero Rincón. Tunja: Instituto de Cultura y Bellas Artes de Boyacá, Ministerio de Educación Nacional, Instituto Andino de Artes Populares, 1989.

López Domínguez, Luis Horacio. "Historia y tendencias de las culturas populares en Boyacá”. Historia y Culturas Populares. Los estudios regionales en Boyacá. Comp. Pablo Mora Calderón y Amado Guerrero Rincón. Tunja: Instituto de Cultura y Bellas Artes de Boyacá, Ministerio de Educación Nacional, Instituto Andino de Artes Populares, 1989.

Ocampo López, Javier. "La identidad del pueblo boyacense". El Lector Boyacense. Ed. Vicente Landino Castro, tomo I. Tunja: Ediciones la Rana y el Águila, 1979.

Ocampo López, Javier. "Música, bailes y cantos nativos”. El Lector Boyacense. Ed. Vicente Landino Castro, tomo II. Tunja: Ediciones la Rana y el Águila, 1980.

Ocampo López, Javier. "Los fundamentos históricos en la formación de los pueblos de Boyacá”. Historia y Culturas Populares. Los estudios regionales en Boyacá. Comp. Pablo Mora Calderón y Amado Guerrero Rincón. Tunja: Instituto de Cultura y Bellas Artes de Boyacá, Ministerio de Educación Nacional, Instituto Andino de Artes Populares, 1989.

Wiesner Gracia, Luis. "Historia prehispánica y permanencias culturales". Historia y Culturas Populares. Los estudios regionales en Boyacá. Comp. Pablo Mora Calderón y Amado Guerrero Rincón. Tunja: Instituto de Cultura y Bellas Artes de Boyacá, Ministerio de Educación Nacional, Instituto Andino de Artes Populares, 1989.

\section{Artículos de revistas}

Araque, Jaime. "Visibilización y difusión de la música tradicional campesina en Boyacá y la región, como herramienta de paz". Revista Principia Iuris 22 (2014): 39-50.

Barrera Aguilera, Óscar Javier. "Folclor, indigenismo y mestizaje durante la república liberal”. Maguaré 23 (2009): 133-153.

Gómez Vergara, Max. "Cumplesiglos de Ventaquemada". Repertorio Boyacense Órgano de la Academia Boyacense de Historia, enero-junio. (1978): 4415- 4419.

Londoño, María Eugenia y Tobón, Alejandro. "Bandola, tiple y guitarra: de las fiestas populares a la música de cámara”. Artes, la Revista 7, 4 (2004): 44-68. 
Martínez Zulaica, Antonio. "El paisaje y el hombre boyacense". Pensamiento y Acción 1 (1978).

Miñana Blasco, Carlos. "Entre el folklore y la etnomusicología. 60 años de estudios sobre la música popular tradicional en Colombia". A Contratiempo. Revista de música en la cultura 11 (2000): 36-49.

Moreno Alaix, Luis Ernesto. "Información folclórica”. Pensamiento y Acción 34. (1978): 10-21.

Rojas Parra, Francy Marizol. "La carranga como escenario vivo de la tradición e identidad cultural local y regional del Departamento de Boyacá". UNAD 12 (2013): 183-191.

Sánchez Amaya, Tomás y Acosta Ayerbe, Alejandro. "Música popular campesina, usos sociales, incursión en escenarios escolares y apropiación por los niños y niñas: la propuesta musical de Velosa y los Carrangueros". Revista Latinoamericana de Ciencias Sociales 6, 1 (2008): 111-146.

\section{Tesis y trabajos de grado}

Ávila Torres, Darwin Rodrigo. "De campesinos y carrangueros. Representaciones del Campesinado cundiboyacense 1976- 1990”. Tesis inédita de Maestría en Historia, Universidad Javeriana, 2018.

Garzón Cano, José Alexander. "Características interpretativas de la música carranguera". Trabajo de grado inédito de Maestro en Música, Universidad de Cundinamarca, 2017.

Ocampo Hernández, Nicole. "Las músicas campesinas carrangueras en la construcción de un territorio". Tesis inédita de Maestría en Patrimonio Cultural y Territorio, Universidad Javeriana, 2014.

Paone, Renato. "La música carranguera". Trabajo de grado inédito de Estudios de Música, Escuela Popular de Arte, 1999.

\section{Publicaciones en Internet}

http://www.youtube.com/watch?v =KzmGAjC3URQ (2018).

https://www.youtube.com/watch?v=QMqpd8Kz-G8\&t=46s (2018).

https://www.youtube.com/watch?v=Fg_Z1KWK5HQ (2018).

https://www.youtube.com/watch?v=nTdJniLXVxU (2018). 